\title{
Trans-resveratrol concentrations and antimutagenic potential of juice from the grape cultivars Vênus, BRS Violeta and Isabel
}

\author{
N.C.V. Polonio ${ }^{1}$, C.L.M.S.C. Rocha ${ }^{1}$ and E. Clemente ${ }^{2}$ \\ ${ }^{1}$ Departamento de Biotecnologia, Genética e Biologia Celular, \\ ${ }^{2}$ Departamento de Química, Universidade Estadual de Maringá, \\ Maringá, PR, Brasil \\ Corresponding author: E. Clemente \\ E-mail: eclemente@uem.br
}

Genet. Mol. Res. 13 (1): 1152-1159 (2014)

Received August 16, 2013

Accepted December 2, 2013

Published February 25, 2014

DOI http://dx.doi.org/10.4238/2014.February.25.1

\begin{abstract}
Grape juice, in addition to being an energetic food, due to its high sugar content, has several compounds that can prevent or treat various types of diseases. Resveratrol is a compound present in grapes that has attracted a lot of interest; in addition to preventing cardiovascular disease linked to lipid metabolism, it has chemopreventive and chemotherapeutic activities. We evaluated the antimutagenic activity and determined the trans-resveratrol content in grape juice from the varieties Vênus, BRS Violeta and Isabel. The grape juices from the three cultivars and the resveratrol solution were tested in the methG1 system in Aspergillus nidulans. The conidia from the biAlmethGl strain were treated for $4 \mathrm{~h}$ in $10 \%$ grape juice (v/v). After washing, the conidia were placed in selective media to analyze survival and mutations. The standard resveratrol solution and the grape juice of the cultivar Isabel, both with a trans-resveratrol content of $1 \mathrm{mg} /$ $\mathrm{mL}$, presented antimutagenic potential in this test system because the frequency of mutation of the treatments was significantly lower than the frequency of spontaneous mutation. However, grape juice from
\end{abstract}


the varieties Vênus and BRS Violeta, both with a lower quantity of trans-resveratrol, gave weak antimutagenic activity in this test system because the frequency of mutation of the treatments was significantly higher than the frequency of spontaneous mutation.

Key words: Phenolic; Red grape varieties; Methionine system (meth G1); Mutagenicity; HPLC

\section{INTRODUCTION}

The search for natural compounds with preventive and curative potential has grown in recent decades, mainly after encouraging results of nutrigenomic works, which have significantly contributed to furnishing information that increases the understanding of how nutrients modulate gene expression and thus influence the cellular metabolism of organisms (Stover, 2004; Afman and Müller, 2006). Thus, it is evident that diet can help prevent and treat diseases and maintain genomic stability, since some dietary compounds can promote the detoxification of mutagens/carcinogens, as well as the synthesis and repair of DNA and apoptosis (Paolini and Nestlé, 2003; Pereira et al., 2005).

The compounds to which possible therapeutic actions have been attributed are known as phenolic compounds. The quantities of total phenolic compounds and anthocyanins in grapes vary according to the species, variety, maturity, and climatic conditions (Kanner et al., 1994; Mazza, 1995).

Grape juice, especially the derivatives of the red grape cultivars, is also a source of phenolic compounds, for example, catechin, epicatechin and anthocyanidin. However, in juices, the quantities of these compounds vary according to diverse factors such as the method of preparation chosen, pressing yield, time and temperature of maceration, stabilization and filtration. Hot extraction contributes to a higher concentration of phenolics in the juice (Arnold et al., 1980; Creasy and Creasy, 1998; Frankel et al., 1998). However, the use of high temperatures during extraction, pasteurization and storage can cause losses in the quantity of phenolic compounds, mainly due to the degradation of anthocyanins (Dergal et al., 1993).

Resveratrol was found in scientific studies to be the main health-protective factor found in wines and grape juice. It is a phytoalexin from the class of stilbenes and therefore a non-flavonoid phenolic compound, naturally found in many plants (not exclusively in fruit) to protect them from microorganisms such as fungi. In grapes, it can be found in the skin and in substantial quantities in the pulp, rachises, vine leaves and even in the seeds, with the highest concentration in the skin, which contains 50-100 micrograms per gram (Jang et al., 1997; Penna and Hecktheuer, 2005).

According to Amerine and Joslyn (1987), in the grape, the rachis contains 1 to 4\%, the skin about 1 to $2 \%$ and the seeds 5 to $8 \%$ phenolic compounds, such as resveratrol. The most abundant sources of these compounds are the varieties Vitis vinifera, V. labrusca and $V$. muscadine (Waterhouse, 1995).

Studies demonstrate that since resveratrol is an antioxidant, it blocks reactions with free radicals that promote the aging process of tissues in the human body, as well as the appearance of different forms of cancer. It is considered responsible for anticancer activities, blocking the development of neoplastic processes and acting in the three stages of cancer (initiation, promotion and progression) (Stavric, 1994; Jang et al., 1997). 
The daily ingestion of 125 to $480 \mathrm{~mL}$ juice from red grapes, especially the varieties of Vitis vinifera, is capable of increasing antioxidant activity (Day et al., 1997; Osman et al., 1998; Freedman et al., 2001; O'Byrne et al., 2002). It also has the capacity to decrease the incidence of cardiovascular diseases and inhibit tumor processes by reducing oxidative damage to DNA (Sánchez-Moreno et al., 1999; Vinson et al., 2001; Singletary et al., 2003; Park et al., 2003).

In vitro assays have shown that grape juice reduces the oxidation of low-density lipoprotein cholesterol and improves endothelial function, increasing the vasodilation of the brachial artery and the mean blood flow in patients with coronary heart disease. In animal models, the daily consumption of grape juice decreased hypercholesterolemia and reduced the initiation of atherosclerosis (Stein et al., 1999; Shanmuganayagam et al., 2007).

The objective of the present study was to evaluate the antimutagenic activity of three varieties of grape (Vênus, BRS Violeta and Isabel), using the meth $G 1$ system in Aspergillus nidulans, and to relate this property to trans-resveratrol content determined by liquid chromatography.

\section{MATERIAL AND METHODS}

The juices were made from three grape varieties: Vênus (Marialva, Paraná State/2006), BRS Violeta (Jales, São Paulo State/2006) and Isabel (Bento Gonçalves, Rio Grande do Sul State/2007).

After the harvest, the grapes were washed in water and healthy-looking ones were selected. After draining the excess water, the juice was made according to the method described by Rizzon (1998), using an 18-kg juice extractor in which the juice is steam-extracted by means of a small gas stove. The grapes were placed (with seeds) in the juice extractor. After $30 \mathrm{~min}$, the juice sample was placed in $500-\mathrm{mL}$ bottles previously sterilized. The containers were then closed with a plastic cap and submitted to pasteurization for $20 \mathrm{~min}$. They were then covered with aluminum foil and stored at $4^{\circ} \mathrm{C}$.

The juice samples were centrifuged at 10,000 rpm for $10 \mathrm{~min}$ and filtered through a cellulose membrane $(0.45-\mu \mathrm{m}$ pore size), using a vacuum pump. A $20-\mu \mathrm{L}$ aliquot of each sample was injected in a chromatograph.

The standard used to construct the analytical curve was trans-resveratrol. A calibration curve (concentrations of $0.1,2.5,5.0$, and $10.0 \mathrm{mg} / \mathrm{L}$ ) was built to analyze the juice of Vênus and BRS Violeta grapes. The calibration curve for the Isabel grape included the following concentrations: $0.1,1.0,2.5,5.0$, and $10.0 \mathrm{mg} / \mathrm{L}$.

Resveratrol was quantified by high-performance liquid chromatography, according to Souto et al. (2001). The equipment used to analyze the juices of the grapes BRS Violeta and Vênus was a Star chromatography workstation (Varian Instruments) consisting of: a reciprocating piston pump (model 240), operating isocratically with an automatic Varian injector (ProStar 410 Autosampler) equipped with a $20-\mu \mathrm{L}$ sample loop, and a spectrophotometric diode array detector (model ProStar 350 with the PolyView program). The chromatographic column used was the RP-18 microsorb C18 $(250 \mathrm{~mm} \times 4.6 \mathrm{~mm}, 5 \mu \mathrm{m})$. The mobile phase was composed of acetonitrile:water (25:75), $\mathrm{pH} 3.0$, adjusted with phosphoric acid $\left(\mathrm{H}_{3} \mathrm{PO}_{4}\right)$ (Merck, flow rate of $1.5 \mathrm{~mL} / \mathrm{min}$ ). The resveratrol peak was detected at $306 \mathrm{~nm}$.

The Shimadzu chromatograph was used to analyze the juice of the Isabel grape. This equipment has the data acquisition system LC Workstation - CLASS A-VP containing a double-reciprocating piston pump (LC-10ATvp-228-39001-92); a forced air-circulation-type 
column oven (CTO-10Avp-228-34610-92); a Rheodyne manual injector coupled to a $20-\mu \mathrm{L}$ sample loop; and a UV-visible detector (SPD-10AVvp-228-39301-92), with deuterium (190$370 \mathrm{~nm})$ and tungsten $(371-900 \mathrm{~nm})$ lamps. The signals of the compounds were monitored at $306 \mathrm{~nm}$.

The identification of the trans-resveratrol was based on the UV peak retention times, with the purity of the peaks confirmed through the use of a diode array detector. The quantification of resveratrol was made by external standardization, which resulted in calibration curve formulas for trans-resveratrol of $y=-87499.10071+627364.79562 x(r=0.99977)$ for Vênus and BRS Violeta cultivars and $\mathrm{y}=-7895.1121+89532.27745 \mathrm{x}(\mathrm{r}=0.99987)$ for cultivar Isabel (in $\mathrm{mg} / \mathrm{L}$ ). The detection (3X) and quantification (10X) limits were obtained by the signal/ noise ratio.

The haploid strain used for the mutagenicity and antimutagenicity tests, biAlmethG1, was originated in Glasgow (Scotland) and is a biotin and methionine auxotroph (Lilly, 1965).

The strain biAlmeth $G 1$ was grown on complete medium $(\mathrm{CM})$ for conidium production. The selective medium (SM) for analysis of the mutants was the minimal medium (MM), supplemented with biotin $(0.02 \mu \mathrm{g} / \mathrm{mL})$. The medium for the survival test (selective MM - SMM) was prepared using the same composition of the SM plus methionine $(50 \mu \mathrm{g} / \mathrm{mL})$.

Five-day-old conidium colonies grown on $\mathrm{CM}$ at $37^{\circ} \mathrm{C}$ were suspended in a $0.1 \%$ Tween 80 solution in water, vortexed for $5 \mathrm{~min}$, and filtered through a sterile glass fiber filter. The conidium solution was divided into six samples: the control (C) without grape juice, and five treatments (Vênus juice, BRS Violeta juice, frozen Isabel juice, fresh Isabel juice) (10\%, $\mathrm{v} / \mathrm{v})$ and a standard solution of $1 \mathrm{mg} / \mathrm{mL}$ resveratrol $(10 \%, \mathrm{v} / \mathrm{v})$. The treatment lasted $4 \mathrm{~h}$.

After three centrifugations and resuspensions in water to remove the treatment (juice and resveratrol solution), each sample was placed in the SM. As regards survival analysis, the original sample was diluted, added to $10 \mathrm{SMM}$ plates for each sample (control and treatments) and incubated for 3 days at $37^{\circ} \mathrm{C}$. In the case of mutant analysis, $10 \mathrm{SM}$ plates were inoculated with original samples and incubated for 5 days at $37^{\circ} \mathrm{C}$. Each experiment was carried out three times.

The number of viable conidia per milliliter of suspension of each sample was obtained by the mean count of colonies in each group of 10 SMM plates. The mutation frequency was the ratio between the total number of colonies of each group of $10 \mathrm{SM}$ plates (mutants per $\mathrm{mL}$ ) and viable conidia per milliliter. Each grape juice treatment and resveratrol solution was analyzed by determining the average survival and mutation frequencies of the three repetitions.

The criterion for the positive/negative conclusion for mutagenesis was the linear correlation between mutation frequency and the logarithm of the survival fraction, described by Munson and Goodhead (1977), adapted for the methG1 test by Scott et al. (1982).

The control values result in two linear slopes $\mathrm{m}_{\mathrm{C}}{ }^{\prime}$ and $\mathrm{m}_{\mathrm{C}}{ }^{\prime}$. The treatment values result in a linear slope $\mathrm{m}_{\mathrm{T}}$. If $\mathrm{m}_{\mathrm{T}}>\mathrm{m}_{\mathrm{C}}{ }^{\prime}$, the treatment is considered mutagenic; if $\mathrm{m}_{\mathrm{C}}{ }^{\prime}<\mathrm{m}_{\mathrm{T}}<\mathrm{m}_{\mathrm{C}}{ }^{\prime \prime}$, the treatment has a questionable positive effect; if $\mathrm{m}_{\mathrm{T}}<\mathrm{m}_{\mathrm{C}}$ ', the treatment has no mutagenic effect in this test.

This test was adapted to antimutagenic analysis by Rodrigues et al. (2003). Accordingly, the treatment values result in two linear slopes $\mathrm{m}_{\mathrm{T}}{ }^{\prime}$ and $\mathrm{m}_{\mathrm{T}}{ }^{\prime}$. The control values result in a linear slope $\mathrm{m}_{\mathrm{C}}$. If $\mathrm{m}_{\mathrm{C}}>\mathrm{m}_{\mathrm{T}}{ }^{\prime}$, the treatment is considered antimutagenic; if $\mathrm{m}_{\mathrm{T}}{ }^{\prime}<\mathrm{m}_{\mathrm{C}}<\mathrm{m}_{\mathrm{T}}{ }^{\prime \prime}$, the treatment has a questionable positive effect; if $\mathrm{m}_{\mathrm{C}}<\mathrm{m}_{\mathrm{T}}{ }^{\prime}$, the treatment has no antimutagenic effect in this test. 


\section{RESULTS}

The analytical curve for trans-resveratrol exhibited good linearity for the injection of 20 $\mu \mathrm{L}$. The detection $(3 \mathrm{X})$ and quantification (10X) limits were obtained by the signal/noise ratio.

Figure 1 shows the amount of trans-resveratrol in different grape cultivars. The data indicated that the Isabel cultivar contained a larger amount of trans-resveratrol than Vênus and BRS Violeta.

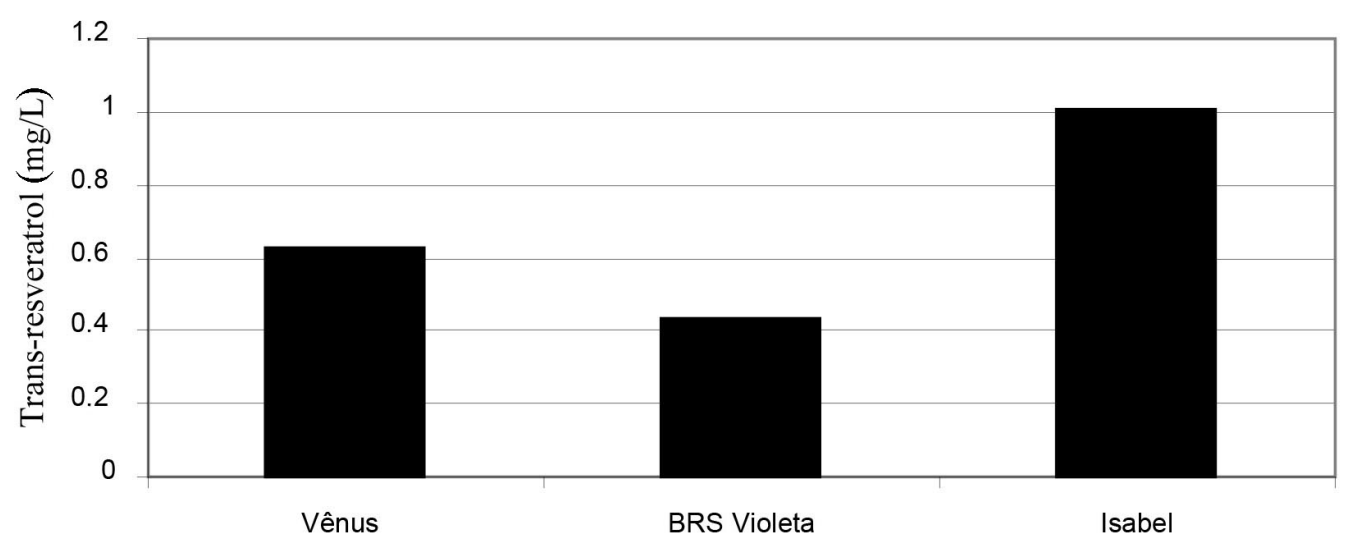

Figure 1. Amount of trans-resveratrol obtained by liquid chromatography from the grape juice of the cultivars Vênus, BRS Violeta, and Isabel.

The methionine system results showed that the Vênus and BRS Violeta juices were mutagenic because the treated conidia displayed lower viability levels and higher mutation frequencies compared to control values (Table 1). Statistical analysis showed that $\mathrm{m}_{\mathrm{T}}$ values were significantly higher than $\mathrm{m}_{\mathrm{C}}$ values (Table 2).

Table 1. Results of viability and mutation frequency obtained by treatment of conidia from the strain biAlmethG1 of Aspergillus nidulans, with 10\% (v/v) grape juice and resveratrol solution.

\begin{tabular}{|c|c|c|}
\hline Treatment & Viable conidia $\times 10^{5} / \mathrm{mL}$ & Mutation frequency $\left(\times 10^{-6}\right)$ \\
\hline$\overline{\mathrm{C} 1}$ & 147.3 & 2.8 \\
\hline $\mathrm{T} 1$ & 103.8 & 5.0 \\
\hline $\mathrm{T} 2$ & 112.5 & 3.8 \\
\hline $\mathrm{C} 2$ & 152.3 & 1.7 \\
\hline T3 & 263.7 & 0.6 \\
\hline T4 & 239.4 & 0.7 \\
\hline T5 & 418.4 & 0.5 \\
\hline
\end{tabular}

T1 = Vênus; T2 = BRS Violeta; T3 = Isabel frozen juice; T4 = Isabel fresh juice; T5 = resveratrol solution; C1 and $\mathrm{C} 2=$ controls. Data are the media of three repetitions.

Isabel frozen and fresh juices and resveratrol solution produced antimutagenic results because the treated conidia had higher viability levels and lower mutation frequencies compared to control values (Table 1 ). $\mathrm{m}_{\mathrm{C}}$ values were significantly higher than the $\mathrm{m}_{\mathrm{T}}$ values (Table 2). 
Table 2. Statistical analysis, according to Munson and Goodhead (1977), of mutation frequencies obtained by treatment of biA1methG1 conidia with grape juice of Vênus (T1), BRS Violeta (T2), frozen juice of Isabel (T3), fresh juice of Isabel (T4) and resveratrol solution (T5).

\begin{tabular}{|c|c|c|c|c|}
\hline \multicolumn{2}{|c|}{ Mutagenicity } & \multicolumn{3}{|c|}{ Antimutagenicity } \\
\hline $\mathrm{T} 1$ & $\mathrm{~T} 2$ & $\mathrm{~T} 3$ & $\mathrm{~T} 4$ & T5 \\
\hline $\begin{array}{l}\mathrm{m}_{\mathrm{C}}^{\prime}=1.4 \\
\mathrm{~m}_{\mathrm{C}}{ }^{\prime \prime}=2.8 \\
\mathrm{~m}_{\mathrm{T}}=2.8^{*}\end{array}$ & $\begin{aligned} \mathrm{m}_{\mathrm{c}}^{\prime} & =1.4 \\
\mathrm{~m}_{\mathrm{C}}^{\prime \prime} & =2.8 \\
\mathrm{~m}_{\mathrm{T}} & =3.7^{*}\end{aligned}$ & $\begin{aligned} \mathrm{m}_{\mathrm{T}}^{\prime} & =0.3 \\
\mathrm{~m}_{\mathrm{T}}^{\prime \prime} & =0.6 \\
\mathrm{~m}_{\mathrm{C}} & =2.0^{*}\end{aligned}$ & $\begin{aligned} \mathrm{m}_{\mathrm{T}}{ }^{\prime} & =0.4 \\
\mathrm{~m}_{\mathrm{T}}^{\prime \prime} & =0.7 \\
\mathrm{~m}_{\mathrm{C}} & =2.2^{*}\end{aligned}$ & $\begin{aligned} \mathrm{m}_{\mathrm{T}}^{\prime} & =0.3 \\
\mathrm{~m}_{\mathrm{T}}{ }^{\prime \prime} & =0.5 \\
\mathrm{~m}_{\mathrm{C}} & =1.2 *\end{aligned}$ \\
\hline
\end{tabular}

Treatment mutation frequency is represented by linear inclination $\left(\mathrm{m}_{\mathrm{T}}\right)$ and spontaneous mutation of control is represented by $\mathrm{m}_{\mathrm{C}}$ * Statistically significant.

\section{DISCUSSION}

Resveratrol acts as a chemopreventive agent, inhibiting tumorigenesis, the formation of free radicals and cyclooxygenase. Resveratrol has expressed an anticarcinogenic effect in a culture of rat breast cells (Spanos et al., 2006).

Different mechanisms for these protective effects have been proposed, such as induction of apoptosis by means of modulation of cellular signaling and regulators of the cell cycle, and inhibition of enzymes with an essential function in cell proliferation (topoisomerase I), although these protective mechanisms are not totally understood (Stagos et al., 2006).

Despite the medicinal properties of wine, its alcohol content limits its consumption. In this respect, grape juice is an alternative because it is composed of the same therapeutic substances as wine without the addition of alcohol. In addition, the antioxidants in grape juice stay in the body longer than those in wine (Bell et al., 2000).

According to Lehmann et al. (2000), with the increase in the consumption of foods containing chemopreventive components, it may be possible to improve protection against the damage caused by mutagenic and carcinogenic compounds. This has led to an increased interest in the possible antimutagenic effects of natural products or chemical compounds and, consequently, an increase in studies in this area.

The initial objective of the present research was to compare grape juices with different levels of resveratrol concentration and their antimutagenic potential. However, two of the culvivars analyzed showed mutagenic properties.

Studies evaluating the antimutagenic activity of grape juice are conflicting. The results of one of them have recently demonstrated that the juice produced using the conventional and organic system was antimutagenic at a concentration of $10 \%(\mathrm{v} / \mathrm{v})$, but mutagenic at $50 \%$ $(\mathrm{v} / \mathrm{v})$ (Dani et al., 2009). Other studies have also indicated that white grape juices have mutagenic activity in strains of Salmonella typhimurium in the Ames test (Patrineli et al., 1996a,b).

Due to the high levels of total phenolic compounds, the oxidation can occur producing quinones with subsequent conversion to semiquinones by electron reduction. These radicals can either interact directly with DNA or produce reactive oxygen species that can cause oxidative stress and DNA damage (Lee et al., 1992; Monks et al., 1991).

According to Patrineli et al. (1996b), polyphenol oxidase catalyzes the oxidation of phenolic compounds in grapes, which produces substances that can cause damages responsible for the mutagenicity of grape juices in the Ames test. Quercetin is a substance with mutagenic activity that occurs naturally in grapes. 
It is possible that concentrations of resveratrol of $1 \mathrm{mg} / \mathrm{mL}$ or higher contribute to overcoming the possible mutagenic effect of the compounds present in grape juice. In fact, the results for the cultivar with this concentration were antimutagenic. The same results were obtained with the resveratrol solution at the same concentration.

According to Fuleki and Ricardo-Da-Silva (2003), the pressing method in the grape juice production process has a great effect on the formation of resveratrol. However, the cultivar has a greater influence on the concentration of resveratrol than the vintage.

Based on the above published studies and the present results, it is important to select cultivars that contain large quantities of resveratrol to obtain the desired antimutagenic effect.

\title{
ACKNOWLEDGMENTS
}

\author{
We thank Reginaldo T. Souza, EMBRAPA agronomic engineer, for providing the grapes.
}

\section{REFERENCES}

Afman L and Müller M (2006). Nutrigenomics: from molecular nutrition to prevention of disease. J. Am. Diet. Assoc. 106: 569-576.

Amerine A and Joslyn MA (1987). Composition of Grapes and Distribution of Phenolics From Table Wines, the Technology of Their Production. University of California Press, Berkeley, 234-238.

Arnold RA, Noble AC and Singleton VL (1980). Bitterness and astringency of phenolic fractions in wine. J. Agric. Food Chem. 28: 675-678.

Bell JR, Donovan JL, Wong R, Waterhouse AL, et al. (2000). (+)-Catechin in human plasma after ingestion of a single serving of reconstituted red wine. Am. J. Clin. Nutr. 71: 103-108.

Creasy LL and Creasy MT (1998). Grape chemistry and the significance of resveratrol: an overview. Pharm. Biol. 36: 8-13.

Dani C, Oliboni LS, Umezu FM, Pasquali MA, et al. (2009). Antioxidant and antigenotoxic activities of purple grape juice - organic and conventional - in adult rats. J. Med. Food 12: 1111-1118.

Day AP, Kemp HJ, Bolton C, Hartog M, et al. (1997). Effect of concentrated red grape juice consumption on serum antioxidant capacity and low-density lipoprotein oxidation. Ann. Nutr. Metab. 41: 353-357.

Dergal SB, Rodriguez BH and Morales AA (1993). Química de los Alimentos. 3rd edn. Longman de México, Nancalpon de Juárez, 388-397.

Frankel EN, Bosanek CA, Meyer AS, Silliman K, et al. (1998). Commercial grape juice inhibits the in vitro oxidation of human low-density lipoproteins. J. Agric. Food Chem. 46: 834-838.

Freedman JE, Parker C III, Li L, Perlman JA, et al. (2001). Select flavonoids and whole juice from purple grapes inhibit platelet function and enhance nitric oxide release. Circulation 103: 2792-2798.

Fuleki T and Ricardo-Da-Silva JM (2003). Effects of cultivar and processing method on the contents of catechins and procyanidins in grape juice. J. Agric. Food Chem. 51: 640-646.

Jang M, Cai L, Udeani GO, Slowing KV, et al. (1997). Cancer chemopreventive activity of resveratrol, a natural product derived from grapes. Science 275: 218-220.

Kanner J, Frankel E, Granit R, German B, et al. (1994). Natural antioxidants in grapes and wines. J. Agric. Food Chem. 42: 64-69.

Lee CS, Hartley JA, Berardini MD, Butler J, et al. (1992). Alteration in DNA cross-linking and sequence selectivity of a series of aziridinylbenzoquinones after enzymatic reduction by DT-diaphorase. Biochemistry 31: 3019-3025.

Lehmann M, Graf U, Reguly ML and Rodrigues De Andrade HH (2000). Interference of tannic acid on the genotoxicity of mitomycin C, methylmethanesulfonate, and nitrogen mustard in somatic cells of Drosophila melanogaster. Environ. Mol. Mutagen. 36: 195-200.

Lilly LJ (1965). An investigation of the suitability of the suppressors of meth 1 in Aspergillus nidulans for the study of induced and spontaneous mutation. Mutat. Res. 2: 192-195.

Mazza G (1995). Anthocyanins in grapes and grape products. Crit. Rev. Food Sci. Nutr. 35: 341-371.

Monks A, Scudiero D, Skehan P, Shoemaker R, et al. (1991). Feasibility of a high-flux anticancer drug screen utilizing a diverse panel of human tumor cell lines in culture. J. Natl. Cancer Inst. 83: 757-766. 
Munson RJ and Goodhead DT (1977). The relation between induced mutation frequency and cell survival - a theoretical approach and an examination of experimental data for eukaryotes. Mutat. Res. 42: 145-160.

O’Byrne DJ, Devaraj S, Grundy SM and Jialal I (2002). Comparison of the antioxidant effects of Concord grape juice flavonoids alpha-tocopherol on markers of oxidative stress in healthy adults. Am. J. Clin. Nutr. 76: 1367-1374.

Osman HE, Maalej N, Shanmuganayagam D and Folts JD (1998). Grape juice but not orange or grapefruit juice inhibits platelet activity in dogs and monkeys. J. Nutr. 128: 2307-2312.

Paolini M and Nestlé M (2003). Pitfalls of enzyme-based molecular anticancer dietary manipulations: food for thought. Mutat. Res. 543: 181-189.

Park YK, Park E, Kim JS and Kang MH (2003). Daily grape juice consumption reduces oxidative DNA damage and plasma free radical levels in healthy Koreans. Mutat. Res. 529: 77-86.

Patrineli A, Clifford MN, Walker R and Ioannides C (1996a). Mutagenicity of white grape juice in the Ames tes. Food Chem. Toxicol. 34: 559-562.

Patrineli A, Clifford MN and Ioannides C (1996b). Contribution of phenols, quinones and reactive oxygen species to the mutagenicity of white grape juice in the Ames test. Food Chem. Toxicol. 34: 869-872.

Penna NG and Hecktheuer LHR (2005). Vinho e saúde: uma revisão. Infarma 16: 64-67.

Pereira F, Machado JC and Almeida MDV (2005). Nutrigenética e nutrigenómica: o admirável mundo novo? Nutrícias 5: 54-55.

Rizzon LA (1998). Elaboração de Suco de Uva na Propriedade Vitícola. Embrapa Uva e Vinho, Bento Gonçalves.

Rodrigues SB, Jabor IAS, Silva GGM and Rocha CLMSC (2003). Avaliação do potencial antimutagênico do Cogumelo do Sol (Agaricus blazei) no sistema methG1 em Aspergillus (=Emericella) nidulans. Acta Sci. Biol. Sci. 25: 513-517.

Sánchez-Moreno C, Larruari JA and Calixto-Saura F (1999). Free radical scavenging capacity and inhibition of lipid oxidation of wines, grape juices and related polyphenolic constituents. Food Res. Int. 32: 407-412.

Scott BR, Dorn GL, Kafer E and Stafford R (1982). Aspergillus nidulans: systems and results of tests for induction of mitotic segregation and mutation. II. Haploid assay systems and overall response of all systems. A report of the U.S. EPA Gene-Tox Program. Mutat. Res. 98: 49-94.

Shanmuganayagam D, Warner TF, Krueger CG, Reed JD, et al. (2007). Concord grape juice attenuates platelet aggregation, serum cholesterol and development of atheroma in hypercholesterolemic rabbits. Atherosclerosis 190: 135-142.

Singletary KW, Stansbury MJ, Giusti M, Van Breemen RB, et al. (2003). Inhibition of rat mammary tumorigenesis by concord grape juice constituents. J. Agric. Food Chem. 51: 7280-7286.

Souto AA, Carneiro MC, Seferin M and Senna MJH (2001). Determination of trans-resveratrol concentrations in Brazilian red wines by HPLC. J. Food Compos. Anal. 14: 441-445.

Spanos M, Gerogiannaki-Christopoulou M, Athanasopoulos P and Ifigenia NK (2006). Trans-resveratrol in wines from the major Greek red and white grape varieties. Food Control. 17: 700-706.

Stagos D, Kazantzoglou G, Theofanidou D, Kakalopoulou G, et al. (2006). Activity of grape extracts from Greek varieties of Vitis vinifera against mutagenicity induced by bleomycin and hydrogen peroxide in Salmonella typhimurium strain TA102. Mutat. Res. 609: 165-175.

Stavric B (1994). Antimutagens and anticarcinogens in foods. Food Chem. Toxicol. 32: 79-90.

Stein JH, Keevil JG, Wiebe DA, Aeschlimann S, et al. (1999). Purple grape juice improves endothelial function and reduces the susceptibility of LDL cholesterol to oxidation in patients with coronary artery disease. Circulation 100 : $1050-1055$

Stover PJ (2004). Nutritional genomics. Physiol. Genomics 16: 161-165.

Vinson JA, Su X, Zubik L and Bose P (2001). Phenol antioxidant quantity and quality in foods: fruits. J. Agric. Food Chem. 49: 5315-5321.

Waterhouse AL (1995). Wine and heart disease. Chem. Ind. 1: 338-341. 